\title{
Genetic signature of prostate cancer resistant to optimized hK2
}

\section{targeted alpha-particle therapy}

\author{
Mesude Bicak ${ }^{1}$, Katharina Lückerath ${ }^{2,3}$, Teja Kalidindi ${ }^{4}$, Sven-Erik Strand ${ }^{5}$, Michael Morris ${ }^{6}$, \\ Caius Radu ${ }^{2,3,7}$, Robert Damoiseaux ${ }^{2}$, Norbert Peekhaus ${ }^{2}$, Austin $\mathrm{Ho}^{2}$, Darren Veach ${ }^{4,9,10}$, Ann- \\ Christin Malmborg Hager ${ }^{10}$, Steven M Larson ${ }^{4,8}$, Hans Lilja ${ }^{6,11,12,13,14}$, Michael R McDevitt ${ }^{4,8}$, \\ Robert J. Klein ${ }^{1, * *}$, David Ulmert ${ }^{2,3,7,15^{*}}$
}

${ }^{1}$ Icahn Institute for Data Science and Genome Technology, Department of Genetics and Genomic Sciences, Icahn School of Medicine at Mount Sinai, New York, NY, USA.

${ }^{2}$ University of California Los Angeles, Department of Molecular and Medical Pharmacology, Los Angeles, CA, USA.

${ }^{3}$ Ahmanson Translational Imaging Division, David Geffen UCLA School of Medicine, Los Angeles, CA, USA

${ }^{4}$ Department of Radiology, Memorial Sloan Kettering Cancer Center, New York, NY, USA.

${ }^{5}$ Division of Oncology and Pathology, Department of Clinical Sciences Lund, Lund University, Lund, Sweden.

${ }^{6}$ Genitourinary Oncology Service, Department of Medicine, Memorial Sloan Kettering Cancer Center, New York, NY, USA.

${ }^{7}$ Jonsson Comprehensive Cancer Center, David Geffen UCLA School of Medicine, Los Angeles, CA, USA.

${ }^{8}$ Department of Radiology, Weill Cornell Medical College, New York, NY, USA.

${ }^{9}$ Radiochemistry and Imaging Sciences Service, Department of Radiology, Memorial Sloan Kettering Cancer Center, New York, NY, USA.

${ }^{10}$ Diaprost AB, Medicon Village, Lund, Sweden.

${ }^{11}$ Department of Laboratory Medicine, Memorial Sloan Kettering Cancer Center, New York, NY, USA.

${ }^{12}$ Department of Translational Medicine, Lund University, Malmö, Sweden.

${ }^{13}$ Nuffield Department of Surgical Sciences, University of Oxford, Oxford, UK.

${ }^{14}$ Department of Surgery, Memorial Sloan Kettering Cancer Center, New York, NY, USA.

${ }^{15}$ Eli and Edythe Broad Center of Regenerative Medicine and Stem Cell Research, UCLA, Los Angeles, CA, USA.

\section{*Corresponding author}

David Ulmert, UCLA, Department of Molecular and Medical Pharmacology, CHS 23-360 650

Charles E Young Drive S, CA-90095, Los Angeles, USA. Telephone: +1 310-825-9474, E-mail:

hulmert@mednet.ucla.edu 
${ }^{* *}$ Co-corresponding author Robert Klein, Telephone: +1 2128248949 . E-Mail: robert.klein@mssm.edu

Conflict of interests: Sven-Erik Strand, Ann-Christin Malmborg-Hager, Hans Lilja and David Ulmert are consultant/advisory board members for and hold ownership interest in Diaprost AB. Sven-Erik Strand and David Ulmert are listed as co-inventors on several patents regarding the humanized form of 11B6, which is owned by Diaprost. Caius Radu is co-founder and holds equity in Sofie Biosciences and Trethera Therapeutics. Intellectual property has been patented by the University of California and has been licensed to Sofie Biosciences and Trethera Therapeutics. This intellectual property was not used in the current study. Hans Lilja has patents on assays to measure intact PSA and a statistical method to detect prostate cancer commercialized as 4 Kscore by OPKO Health, receives royalties from sales of this test, and owns stock in OPKO Health. Steven M. Larson reports receiving commercial research grants from Regeneron and Telix, holds ownership interest (including patents) in Voreyda, Imaginab, and Elucida, and is a consultant/advisory board member for Johnson and Johnson. Memorial Sloan Kettering Cancer Center has filed for IP protection for inventions related to alpha particle technology of which Michael McDevitt is an inventor. Michael McDevitt was a consultant for Actinium Pharmaceuticals, Regeneron, Progenics, Bridge Medicines, and General Electric. No other potential conflict of interest relevant to this article was reported. 


\begin{abstract}
Hu11B6 is a monoclonal antibody that internalizes in cells expressing androgen receptor (AR)regulated prostate specific enzyme human kallikrein 2 (hK2; KLK2). In multiple rodent models,

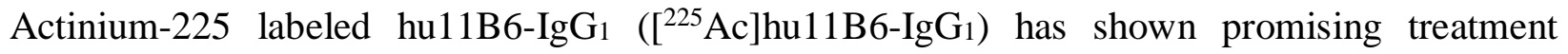
efficacy. In the current study we investigated options to enhance and optimize $\left[{ }^{225} \mathrm{Ac}\right] \mathrm{hu} 11 \mathrm{~B} 6$ treatment. Firstly, we evaluated the possibility of exploiting $\operatorname{IgG}_{3}$, the immunoglobulin $\mathrm{G}$ ( $\operatorname{IgG}$ ) subclass with superior activation of complement and ability to mediate FC-gamma-receptor binding, for immunotherapeutically enhanced hK2 targeted alpha-radioimmunotherapy. Secondly, we compared the therapeutic efficacy of a single high activity vs. fractionated activity. Finally, we used RNA sequencing to analyze the genomic signatures of prostate cancer that progressed after targeted alpha therapy. $\left[{ }^{225} \mathrm{Ac}\right] \mathrm{hu} 11 \mathrm{~B} 6-\mathrm{IgG}_{3}$ was a functionally enhanced alternative to $\left[{ }^{225} \mathrm{Ac}\right]$ hu11B6-IgG 1 but offered no improvement of therapeutic efficacy. Progression free survival was slightly increased with a single high activity compared to fractionated activity. Tumor free animals succumbing after treatment revealed no evidence of treatment associated toxicity. In addition to upregulation of canonical aggressive prostate cancer genes, such as MMP7, ETV1, NTS and SCHLAP1, we also noted a significant decrease in both KLK3 (PSA) and FOLH1 (PSMA) but not in $A R$ and $K L K 2$, demonstrating efficacy of sequential $\left[{ }^{225} \mathrm{Ac}\right]$ hu11B6 in a mouse model.
\end{abstract}




\section{Introduction}

Actinium-225 labeled antibodies and small molecules targeting prostate specific antigen (PSMA) are currently being evaluated in clinical trials, and reports have already shown promising therapeutic results in prostate cancer $(\mathrm{PCa})$ patients resistant to androgen receptor $(\mathrm{AR})$-inhibiting drugs ${ }^{1-3}$. Unfortunately, toxicities generated by off-target accumulation in radio-sensitive tissues, such as salivary glands and kidneys, is of growing concern ${ }^{4,5}$. In addition, PSMA expression decreases with increasing AR activity and has been shown to be unevenly expressed in metastases 6-9. We have developed an antibody-based platform that targets human kallikrein 2 (hK2), an AR regulated prostate enzyme, specifically expressed at abundant levels in prostate derived tissues. In enzalutamide resistant disease, in which the glucocorticoid receptor (GR) drives the AR-pathway, PSMA expression is lost while hK2 is still highly expressed ${ }^{10}$. Our group has previously reported on the targeting specificity, efficacy and biological response of radiolabeled hu11B6 as an immunotheranostic vehicle. Preclinical evaluations have been carried out in multiple immunodeficient and immunocompetent, rodent disease models as well as in non-human primates 3,11-14. In addition, studies of the uptake mechanism have revealed that hu11B6 is internalized by hK2 expressing cells via a mechanism driven by the neonatal Fc receptor (FcRn); while uncomplexed hu11B6 is released from the cell by recycling endosomes after binding to FcRn, the hu11B6-hK2 complex is routed to lysosomes for processing ${ }^{12}$. The proximity of the internalized radionuclide-labeled hu11B6 to the nucleus results in efficient cell kill, which is further accelerated by inherent AR and hK2 upregulation related to DNA-repair ${ }^{3}$.

In the current report we investigated alternative strategies to further improve the therapeutic efficacy of hu11B6. In the field of nuclear medicine, the fragment crystallizable (Fc) 
is commonly ablated to increase blood clearance. However, these modifications also obliterate possibilities to exploit radiolabeled monoclonal antibodies (mAbs) to orchestrate Fc-receptor activated cytotoxic effects. IgG 3 activates complement and Fc-gamma-receptor (Fc $\gamma \mathrm{R})$-mediated functions more efficiently than other subclasses. We therefore investigated if changing the subclass of hu11B6 from $\operatorname{IgG}_{1}$ to $\mathrm{IgG}_{3}$ could improve therapeutic efficacy. However, wild-type $\mathrm{IgG}_{3}$ has low FcRn binding capacity due to an arginine at amino acid (aa) position 435 (R435), abrogating cellular internalization ${ }^{15}$. To overcome this, we constructed a H435 (i.e., histidine at aa 435) containing hu11B6 $\mathrm{IgG}_{3}$ allotype, generating hu11B6- $\operatorname{IgG}_{3}{ }^{\mathrm{R} 435 \mathrm{H}}$. As another optimization step, we evaluated therapeutic efficacy of a single high activity vs. two lower activity fractions. Lastly, we examined the genetic profile of PCa tumors resistant to [ $\left.{ }^{225} \mathrm{Ac}\right] \mathrm{hu} 11 \mathrm{~B} 6-\mathrm{Ig} \mathrm{G}_{1}$ therapy. In summary, while $\mathrm{IgG}_{3}$ has shown increased immunotherapeutic efficacy compared to $\operatorname{IgG}_{1}{ }^{16-18}$, no advantage was shown when applied as a radiolabeled compound targeting hK2. Although susceptible to retreatment, tumors relapsing after $\left[{ }^{225} \mathrm{Ac}\right] \mathrm{hu} 1 \mathrm{~B} 6-\mathrm{Ig} \mathrm{G}_{1}$ showed upregulation of several oncogenes related to aggressive disease. 


\section{Results}

Radiochemistry. The radiochemical yield for the $\left[{ }^{225}\right.$ Ac]DOTA-hu11B6 product using a one-step labeling method was $60.2 \% \pm 29.3 \%(n=5)$. The product was $98.5 \% \pm 2.0 \%(n=5)$ radiochemically pure and the specific activity was $0.068 \mathrm{Ci} / \mathrm{g} \pm 0.032 \mathrm{Ci} / \mathrm{g}(2.516 \mathrm{GBq} / \mathrm{g} \pm 1.184 \mathrm{GBq} / \mathrm{g} ; \mathrm{n}=5)$. The radiochemical yields for the four hu11B6 combinations prepared using a two-step radiolabeling method were as follows: $\left[{ }^{225} \mathrm{Ac}\right] \mathrm{hu} 11 \mathrm{~B} 6-\mathrm{IgG}_{1}$ (native $\left.\mathrm{IgG}_{1}\right), 3.7 \% \pm 2.1 \%(\mathrm{n}=13)$; $\left[{ }^{225} \mathrm{Ac}\right] \mathrm{hu} 11 \mathrm{~B} 6-$ $\mathrm{IgG}_{1}{ }^{\mathrm{H} 435 \mathrm{~A}}\left(\mathrm{H} 435 \mathrm{~A}\right.$ mutant $\left.\mathrm{IgG}_{1}\right), 3.1 \% \pm 1.0 \%(\mathrm{n}=3) ;\left[{ }^{225} \mathrm{Ac}\right]$ hu11B6-IgG $\left(\right.$ wild-type $\left.\operatorname{IgG} \mathrm{G}_{3}\right)$ $11.0 \%(\mathrm{n}=1)$; and $\left[{ }^{225} \mathrm{Ac}\right] \mathrm{hu} 11 \mathrm{~B} 6-\mathrm{IgG}_{3}{ }^{\mathrm{R} 435 \mathrm{H}}(\mathrm{R} 435 \mathrm{H}$ mutant $\mathrm{IgG}), 9.1 \%(\mathrm{n}=1)$. The radiochemical purity was as follows: native $\operatorname{IgG}_{1}, 99.3 \% \pm 0.51 \%$; H435A mutant $\mathrm{IgG}_{1}, 99.7 \% \pm 0.21 \%$; wildtype $\mathrm{IgG}_{3}, 99.8 \%$; and $\mathrm{R} 435 \mathrm{H}$ mutant $\mathrm{IgG}_{3}, 99.8 \%$. The specific activity was as follows: native $\mathrm{IgG}_{1}, 0.079 \mathrm{Ci} / \mathrm{g} \pm 0.055 \mathrm{Ci} / \mathrm{g}(2.923 \mathrm{GBq} / \mathrm{g} \pm 2.035 \mathrm{GBq} / \mathrm{g}) ; \mathrm{H} 435 \mathrm{~A}$ mutant $\mathrm{IgG}_{1}, 0.059 \mathrm{Ci} / \mathrm{g} \pm$ $0.018 \mathrm{Ci} / \mathrm{g}(2.183 \mathrm{GBq} / \mathrm{g} \pm 0.666 \mathrm{GBq} / \mathrm{g})$; wild-type $\mathrm{IgG}_{3}, 0.068 \mathrm{Ci} / \mathrm{g}(2.516 \mathrm{GBq} / \mathrm{g})$; and R435H mutant $\mathrm{IgG}_{3}, 0.066 \mathrm{Ci} / \mathrm{g}(2.442 \mathrm{GBq} / \mathrm{g})$. Comparable radiochemical purity and specific activities were achieved in either process. The KD of $\left[{ }^{225}\right.$ Ac]DOTA-hu11B6, DOTA-hu11B6, and hu11B6 for recombinant $\mathrm{hK}-2$ was $16.7,16.3$, and $15.0 \mathrm{nM}$, respectively and indicated that the DOTA conjugation and subsequent ${ }^{225}$ Ac-radiolabeling did not affect affinity of the antibody for target analyte.

The impact of IgG subclass on $\left[{ }^{225} A c\right] h u 11 B 6$ pharmacokinetics. Compared to wildtype $\left[{ }^{225} \mathrm{Ac}\right]$ hu11B6-IgG 3 , significantly ( $\mathrm{p}=0.0139$ for all) higher target tissue uptakes were noticed in the GEMM model for FcRn optimized $\left[{ }^{225} \mathrm{Ac}\right]$ hu11B6- $\mathrm{IgG}_{3}{ }^{\mathrm{R} 435 \mathrm{H}}$. In the ventral-, anterior-, and dorsal/lateral prostate lobes of $\mathrm{Hi}-M y c \times$ pb_KLK2 mice, percent injected activity per gram $(\% \mathrm{IA} / \mathrm{g} ; \pm \mathrm{SD})$ of $\left[{ }^{225} \mathrm{Ac}\right] \mathrm{hu} 11 \mathrm{~B} 6-\mathrm{IgG}_{3}{ }^{\mathrm{R} 435 \mathrm{H}}$ were $7.75 \pm 1.99,3.60 \pm 1.14$ and $7.08 \pm 3.65$, while 
$\% \mathrm{IA} / \mathrm{g}( \pm \mathrm{SD})\left[{ }^{225} \mathrm{Ac}\right] \mathrm{hu} 11 \mathrm{~B} 6-\mathrm{IgG}_{3}$ were $2.48 \pm 0.50,1.03 \pm 0.17$ and $0.80 \pm 0.26$, respectively, at $10 \mathrm{~d}$ post-injection (Figure 1a). LNCaP-AR tumor models led to similar findings; $\left[{ }^{225} \mathrm{Ac}\right] \mathrm{hu} 11 \mathrm{~B} 6-$ $\mathrm{IgG}_{3}{ }^{\mathrm{R} 435 \mathrm{H}}$ showed significantly $(\mathrm{p}=0.1653$ at $4 \mathrm{~h}, \mathrm{p}=0.0003$ at $72 \mathrm{~h}, \mathrm{p}=0.0132$ at $240 \mathrm{~h}$ p.i.) higher tumor uptake compared to $\left[{ }^{225} \mathrm{Ac}\right] \mathrm{hu} 11 \mathrm{~B} 6-\mathrm{IgG}_{3}, 8.45 \pm 4.28$ and $0.86 \pm 0.79 \% \mathrm{IA} / \mathrm{g}( \pm \mathrm{SD})$, respectively, at 10d post-injection (Figure 1b). As expected, enhancement of FcRn binding resulted in a strong trend towards longer blood circulation time of $\left[{ }^{225} \mathrm{Ac}\right] \mathrm{hu} 11 \mathrm{~B} 6-\mathrm{IgG}{ }_{3}^{\mathrm{R} 435 \mathrm{H}}$ (vs. $\left[{ }^{225} \mathrm{Ac}\right]$ hu11B6-IgG 3 ) in both genetically modified mouse models (GEMM; $\mathrm{p}=0.0736$ at $240 \mathrm{~h}$ post injection [p.i.]) and tumor xenograft models ( $p=0.0013$ at $4 \mathrm{~h}, \mathrm{p}=0.0552$ at $72 \mathrm{~h}, \mathrm{p}>0.9999$ at $240 \mathrm{~h}$ p.i.). Compared to the $\operatorname{IgG}_{1}$ variant, $\left[{ }^{225} \mathrm{Ac}\right]$ hu11B6- $\operatorname{IgG}_{3}{ }^{\mathrm{R} 435 \mathrm{H}}$ showed significantly lower target tissue accumulation (LNCaP-AR, p=0.0098 and GEMM, p=0.0299 for IgG3 ${ }^{\mathrm{R} 435 \mathrm{H}}$ at $240 \mathrm{~h}$ vs. $\operatorname{IgG}_{1}$ at $400 \mathrm{~h}$ p.i.) and shorter retention time in blood (LNCaP-AR, $\mathrm{p}=0.0056$ and GEMM, $\mathrm{p}=0.4238$ for $\operatorname{IgG} 3^{\mathrm{R} 435 \mathrm{H}}$ at $240 \mathrm{~h}$ vs. $\operatorname{IgG}_{1}$ at $400 \mathrm{~h}$ p.i.) at the final distribution timepoint, while significantly higher ( $\mathrm{p} \leq 0.0174$ for all in both models) accumulation of $\left[{ }^{225} \mathrm{Ac}\right] \mathrm{hu} 11 \mathrm{~B} 6-\mathrm{IgG}_{3}{ }^{\mathrm{R} 435 \mathrm{H}}$ was noted in immunoglobulin degrading organs (i.e., liver and spleen).

The impact of IgG subclass on $\left[^{225}\right.$ Ac] hu11B6 alpha-radioimmunotherapy (RIT) in LNCaP-AR s.c. xenografts. Mice with LNCaP-AR s.c. xenografts were randomized to receive (A) $\left[{ }^{225}\right.$ Ac] $]$ hu11B6$\left.\operatorname{IgG}_{1}(\mathrm{n}=5),(\mathrm{B}){ }^{225} \mathrm{Ac}\right] \mathrm{hu} 11 \mathrm{~B} 6-\mathrm{IgG}_{1}{ }^{\mathrm{H} 435 \mathrm{~A}}\left(\mathrm{IgG}_{1}\right.$ with inhibited $\mathrm{FcRn}$-coupled cellular processes by exchanging histidine 435 to an alanine) $(n=5)$, (C) $\left[{ }^{225} \mathrm{Ac}\right] \mathrm{hu} 11 \mathrm{~B} 6-\operatorname{IgG}_{3}{ }^{\mathrm{R} 435 \mathrm{H}}$ ( $\left.\mathrm{n}=5\right)$ or (D) $\left[{ }^{225} \mathrm{Ac}\right]$ hu11B6-IgG $3(\mathrm{n}=5)$. [ $\left.{ }^{225} \mathrm{Ac}\right] \mathrm{hu11B} 6$ constructs based on FcRn complexing Ig-subforms resulted in significantly better treatment outcomes (Figure 2, Supplemental Figure 1). KaplanMeier analysis of the four treatment groups showed median survival of 18.43 (A), 9.14 (B), 11.42 (C) and 7.86 (D) weeks after administration of $300 \mathrm{nCi}(11 \mathrm{kBq})$, respectively (A vs. B, p<0.0001; 
C vs. D, p=0.0020; A vs. C, p=0.0536) (Figure 2a). Assessment of volumetric effects showed that mice treated with $\left[{ }^{225} \mathrm{Ac}\right] \mathrm{hu} 11 \mathrm{~B} 6-\mathrm{IgG}_{3}{ }^{\mathrm{R} 435 \mathrm{H}}$ had reduced tumor growth kinetics compared to [ $\left.{ }^{225} \mathrm{Ac}\right]$ hu11B6-IgG 3 (Figure 2b). However, [ $\left.{ }^{225} \mathrm{Ac}\right]$ hu11B6-IgG1 outperformed [ ${ }^{225}$ Ac]hu11B6$\mathrm{IgG}_{3}{ }^{\mathrm{R} 435 \mathrm{H}}$ (Figure 2c); at the conclusion of the study, half of the animals treated with the specific and internalizing $\left[{ }^{225} \mathrm{Ac}\right] \mathrm{hu} 1 \mathrm{~B} 6-\mathrm{IgG}_{1}$ drug were alive, while only one animal was alive in the group that received $\left[{ }^{225} \mathrm{Ac}\right] \mathrm{hu} 11 \mathrm{~B} 6-\mathrm{IgG}_{3}{ }^{\mathrm{R} 435 \mathrm{H}}$.

The impact of IgG subclass on $\left[{ }^{225}\right.$ Ac] hul1B6 alpha-RIT in immunocompetent PCa GEMM. 4055 week old hK2-expressing Hi-Myc GEMM were randomized to receive (A) $\left[{ }^{225}\right.$ Ac]hu11B6$\operatorname{IgG}_{1} \quad(n=7), \quad(B) \quad\left[{ }^{225} \mathrm{Ac}\right] h u 11 \mathrm{~B} 6-\operatorname{IgG}_{1}{ }^{\mathrm{H} 435 \mathrm{~A}} \quad(\mathrm{n}=7), \quad(\mathrm{C}) \quad\left[{ }^{225} \mathrm{Ac}\right] \mathrm{hu} 11 \mathrm{~B} 6-\operatorname{IgG}_{3}{ }^{\mathrm{R} 435 \mathrm{H}} \quad(\mathrm{n}=7), \quad(\mathrm{D})$ $\left[{ }^{225} \mathrm{Ac}\right]$ hu11B6- $\operatorname{IgG} 3(\mathrm{n}=7)$ or $(\mathrm{E})$ non-specific $\left[{ }^{225} \mathrm{Ac}\right] \operatorname{IgG} 1(\mathrm{n}=5)$. Kaplan-Meier analysis of these four treatments showed median survival of undefined $(\mathrm{A} ;>50 \%$ of the cohort had survived with [225Ac]hu11B6-IgG 1 ), 8.71 (B), 15.71 (C), 12.0 (D) and 8.72 (E) weeks after administration of $300 \mathrm{nCi}(11 \mathrm{kBq})$, respectively (A vs. B, p=0.0020; C vs. D, p=0.0576; A vs. C, p=0.1197) (Figure 2d). At the end of the study, 4 of 7 (57\%) GEMM were alive in group A but only 1 of 7 (14\%) in group $\mathrm{C}$. These data indicate that an $\mathrm{IgG}_{1}$ based $\mathrm{hK} 2$ targeting compound is more effective than $\mathrm{IgG}_{3}{ }^{\mathrm{R} 435 \mathrm{H}}$ when applied for alpha-particle RIT. Therapeutic effect by ineffective FcRn-binding compounds (B, D) were not significantly different from non-specific $\left[{ }^{225} \mathrm{Ac}\right] \operatorname{IgG} 1$ (B vs E, $p=0.9738 ; D$ vs $E, p=0.5726$ ), showing that efficacy is dependent on a combination of specific targeting and cellular internalization.

Pharmacokinetics of $\left[{ }^{225}\right.$ Ac]hul1B6-IgG1, labeled using a novel 1-step protocol, in s.c. PCa xenografts and immunocompetent PCa GEMM. The one-step labelling protocol based on pre- 
conjugated hu11B6 was developed to facilitate clinical translation. Biodistribution of $\left[{ }^{225} \mathrm{Ac}\right]$ hu11B6 was studied in LNCaP-AR $(K L K 2+)$ s.c. xenografts at 48,120 and $400 \mathrm{~h}$ p.i., in PC3 (KLK2-) s.c. xenografts at $400 \mathrm{hrs}$ p.i. and in 15-30 weeks old hK2-expressing Hi-Myc GEMM at 400 hrs p.i. As expected, uptake of $\left[{ }^{225} \mathrm{Ac}\right]$ hu11B6 increased over time in LNCaP-AR tumors and uptake at 400 hrs p.i. was significantly $(\mathrm{p}=0.0020)$ higher than in PC3 tumors at the same time-point (Figure 3a). In GEMM, the highest specific uptake of [ $\left.{ }^{225} \mathrm{Ac}\right]$ hu11B6 was found in prostate lobes (Figure 3b). In summary, biodistribution profile of 1-step labeled $\left[{ }^{225} \mathrm{Ac}\right] \mathrm{hu} 11 \mathrm{~B} 6$ closely resembled our previously published results based on the 2-step labeled $\left[{ }^{225}\right.$ Ac]hu11B6 compound ${ }^{3}$. Therefore, the one-step labelling protocol was used for all further studies.

Therapeutic efficacy of fractionated vs. single activity $\left[{ }^{225} A c\right]$ hul 1B6-IgG 1 alpha RIT. Bilaterally inoculated LNCaP-AR s.c. xenografts were used in both treatment studies. Therapeutic effects were monitored by tumor size (caliper measurements) and assessment of PSA in blood. In the fractionated treatment experiment, animals $(\mathrm{n}=10)$ were randomized to receive $300 \mathrm{nCi}(11 \mathrm{kBq})$ $\left[{ }^{225}\right.$ Ac $]$ hu11B6 $(n=5)$ or no treatment $(n=5)$. Previously treated mice were given a second injected activity (300 nCi; $11 \mathrm{kBq}) 20$ weeks after the first treatment. Tumors were either fully eradicated or substantially reduced after each treatment round; 5 of $8(63 \%)$ and 2 of $5(40 \%)$ tumors relapsed after the first activity and second activity administration, respectively (Figure 4a; Supplemental Figure 2a). In the single high-activity treatment experiment, xenografts $(n=10)$ were randomized to receive a single activity $600 \mathrm{nCi}(22 \mathrm{kBq})$ of $\left[{ }^{225} \mathrm{Ac}\right]$ hu11B6 $(\mathrm{n}=5)$ or no treatment $(\mathrm{n}=5)$. All tumors were eradicated (tumors not palpable and PSA not detectable); during the study period, only 1 of $6(17 \%)$ tumors relapsed (Figure 4b; Supplemental Figure 2b). Mice that had lost weight ( $\geq 20 \%$ weight loss) at the end of the high-activity study were euthanized and send for 
autopsy evaluation. These reports concluded age-related macroscopic and histopathologic but no treatment-related pathological changes. Comparing fractionated vs. single activity treatment median survival was not reached ( $80 \%$ of the cohort had survived at the conclusion of the study) following $600 \mathrm{nCi}(22 \mathrm{kBq})$, whereas 2x $300 \mathrm{nCi}(2 \times 11 \mathrm{kBq})$ resulted in a median survival of 40.3 weeks after the first treatment ( $\mathrm{p}=0.3186$ vs. high-activity) (Figure $4 \mathbf{c}, \mathbf{d})$.

Transcriptome Sequencing. The transcriptome of tumors relapsing after 2 cycles $\left[{ }^{225} \mathrm{Ac}\right] \mathrm{hu} 11 \mathrm{~B} 6$ ( vs. untreated control tumors, $n=3$ /group) was profiled. RNA-sequencing identified 58,828 genes of which 1,644 (2.8\%; 512 up-, 1,132 down-regulated) were differentially expressed in relapsing tumors. Among the differentially expressed genes (DEG), genes associated with aggressive prostate cancer, such as MMP7 (matrix metalloprotease 7), ETV1 (ETS translocation variant 1), NTS (neurotensin), TMEFF2 (transmembrane protein with EGF-like and two follistatin-like domains 2 ) and SCHLAP1 (SWI/SNF complex antagonist associated with prostate cancer 1), and androgen repressed genes, such as PMP22 (peripheral myelin protein 22), CAMK2N1 (calcium/calmodulin dependent protein kinase II inhibitor 1) and UGT2B17UDP (glucuronosyltransferase family 2 member B17), were significantly up-regulated. In contrast, several AR-regulated genes, e.g. KLK3, FOLH1, PMEPA1 (prostate transmembrane protein, androgen induced 1) and SPOCK1 (Testican-1), were downregulated or remained unchanged (KLK2, TMPRSS2 [transmembrane serine protease 2], LONRF1 [LON peptidase N-terminal domain and RING finger protein 1], KCNN2 [small conductance calcium-activated potassium channel protein 2]). Expression of $A R$ itself was comparable in treated and untreated tumors (Table 1). Figure 5 gives an overview of all DEGs and Tabels 2 and 3 summarize the top 10 upregulated and down-regulated genes. 


\section{Discussion}

Recently approved drugs that target AR signaling such as abiraterone and enzalutamide have rapidly become standard therapies for advanced-stage prostate cancer ${ }^{19,20}$. Initial responses are usually observed, but in an absolute majority of these patients, reactivation of the AR-pathway inevitably occurs within 6 to 12 months. An alternative treatment option is to target tumors using radiolabeled antibodies or small molecules, a technology that is highly dependent on the specificity of the vehicle and target expression in non-malignant tissues. We have developed an antibodybased platform that targets $\mathrm{hK} 2$, an enzyme that is prostate tissue-specific and under direct regulation of AR, the central driver of prostate adenocarcinoma. Our lead antibody, hu11B6, has been thoroughly evaluated for tumor detection and monitoring of disease activity by positron emission tomography and single photon emission computed tomography ${ }^{12,14}$. We have reported that hu11B6 can be applied for RIT applications ${ }^{3,11,13}$. In the current report we aimed to evaluate previously untested and innovative methods that could further increase efficacy. First, we evaluated if therapeutic efficacy could be improved by altering the Fc-subclass. Second, we assessed the impact of dosing strategies. Finally, to determine radio-biological mechanisms that could appropriate combination therapies or elucidate potential drug resistance, we genetically profiled tumors that relapsed after prolonged treatment.

Induction of DNA damage, tumor cell death and modulation of tumor microenvironment are the main effects of ionizing radiation to reduce tumor masses, but also to effectuate the immune system ${ }^{21}$. Therefore, we investigated if the therapeutic efficacy of $\left[{ }^{225} \mathrm{Ac}\right] \mathrm{hu} 11 \mathrm{~B} 6$ could be improved by exploiting the complement-, and Fc $\gamma \mathrm{R}$ binding capacities of the mAb. We constructed an Fc-substituted hu11B6; from $\mathrm{IgG}_{1}-\mathrm{Fc}$ to $\mathrm{IgG}_{3}-\mathrm{Fc}$. Compared to $\mathrm{IgG}_{1}$, wild-type $\mathrm{IgG}_{3}$ has an 
arginine instead of a histidine at the aa position 435. Although both residues are positively charged, arginine does not deprotonate at neutral $\mathrm{pH}$, resulting in a less $\mathrm{pH}$ dependent binding to FcRn. To rescue FcRn-mediated internalization, we introduced a histidine at the aa position $435^{22}$, generating a hu11B6-IgG3-R435H. Indeed, this optimization is critical as almost no effect was noted with $\left[{ }^{225} \mathrm{Ac}\right]$ hu11B6- $\operatorname{IgG} 3$, while $\left[{ }^{225} \mathrm{Ac}\right]$ hu11B6- $\mathrm{IgG}_{3}-\mathrm{R} 435 \mathrm{H}$ produced a relatively potent therapeutic outcome. Biodistribution in immunodeficient tumor models and immunocompetent GEMM indicated that $\left[{ }^{225} \mathrm{Ac}\right] \mathrm{hu} 11 \mathrm{~B} 6-\mathrm{IgG}_{3}-\mathrm{R} 435 \mathrm{H}$ is less stable than its $\mathrm{IgG}_{1}$ counterpart; significantly higher uptake in immunoglobulin-degrading organs were noted. This is probably due to the long hinge region of $\operatorname{IgG}_{3}$, which is more prone to proteolytic degradation ${ }^{23}$.

Based on our results, $\left[{ }^{225} \mathrm{Ac}\right]$ hu11B6-IgG $3-\mathrm{R} 435 \mathrm{H}$ did not show any therapeutic advantage over $\left[{ }^{225} \mathrm{Ac}\right] \mathrm{hu} 11 \mathrm{~B} 6-\mathrm{IgG}_{1}$. However, the lack of increased efficacy could be due to critical differences between mouse and human Fc $\gamma R$ networks. For example, mouse natural killer (NK) cells express mFc $\gamma$ RIII, while human NK cells express hFc $\gamma$ RIIIA. hFc $\gamma$ RIIIA is a key mediator of antibody therapy in humans, while mFcrRIII only modestly contributes to mAb efficacy ${ }^{24,25}$. Therefore, experiments based on GEMM expressing human Fc $\gamma$ Rs would be needed in order to fully elucidate whether RIT efficacy can be enhanced by using Fc-engineered mAbs. Our approach of exploiting Fc-engineered mAbs for RIT is novel. In the field of nuclear medicine, the Fc region has been viewed as redundant and various Fc-edited antibody-like platforms have been invented 26. Omitting the Fc-region decreases the half-life of the antibody by escaping FcRn-interaction and permitting renal clearance. However, Fc contains motifs for activation of both effector immune cells and the classical pathway of the complement (C1q). One of the most important breakthroughs in the field of immunology during the last two decades is the discovery and characterization of the 
Fc-portion interaction with Fc $\gamma \mathrm{R}$ which orchestrates mAb dependent cellular cytotoxicity through cytotoxic effects via agonistic and antagonistic binding ${ }^{27}$. The specific Fc $\gamma \mathrm{R}$ engaged by a given Fc domain is dictated by Fc structure which is determined by the IgG subclass. An example of the multifaceted therapeutic activity are checkpoint-inhibitor mAbs (e.g., anti-CTLA4) that mediate antitumor activity by altering the composition and functional activity of leukocytes within the tumor microenvironment. However, the therapeutic action is also an effect of the capacity of the $\mathrm{mAb}$ to activate $\mathrm{Fc} \gamma \mathrm{R}$ expressing macrophages within the tumor microenvironment ${ }^{28}$. Radiation has been shown to induce immune-modulatory effects. Both preclinical and clinical studies have shown that radiation enhances the activity of immune checkpoint blockers and thereby promotes systemic antitumor responses ${ }^{29}$. The capacity of radiation therapy to promote immune-modulatory effects is now the subject of intense scientific and clinical investigation. Based on these observations, a radiolabeled full sized $\mathrm{mAb}$ might have the unique capacity to target its antigen while inducing immune-modulatory effects and activate Fc receptor mediated cytotoxicity.

Although a single high activity may deliver optimal absorbed dose to kill a larger fraction of tumor cells, fractionated therapy could offer the advantage of lower myelotoxicity and prolonged tumor response. In accordance to previous studies based on $\left[{ }^{177} \mathrm{Lu}\right] \mathrm{hu} 11 \mathrm{~B} 6$, results showed that the therapeutic effect of $\left[{ }^{225} \mathrm{Ac}\right] \mathrm{hu} 11 \mathrm{~B} 6$ is absorbed dose dependent; fewer tumors relapsed in mice treated with a higher activity ${ }^{13,30}$. All of our previous evaluations of $\left[{ }^{225} \mathrm{Ac}\right]$ hu11B6-RIT studies were based on evaluation of a single activity. In the current study, $\left[{ }^{225} \mathrm{Ac}\right]$ hu11B6 treatment was repeated when several mice had relapsed, and relapsed tumors had progressed to a significant volume. Based on tumor and PSA measurements, we did not notice any signs of resistance to treatment when repeated. To retrieve more biologically relevant data, the 
transcriptome of tumors progressing after $\left[{ }^{225} \mathrm{Ac}\right]$ hu11B6 were evaluated by RNA-sequencing. Although the tumor material post-treatment was limited since only few tumors relapsed and analysis was only based on a single tumor model, the material displays a unique profile. We have previously reported that early effects (400 h after treatment initiation) of $\left[{ }^{225} \mathrm{Ac}\right] \mathrm{hu} 11 \mathrm{~B} 6 \mathrm{RIT}$ include DNA-repair associated AR-induction similar to external beam therapy which resulted in increased expression of hK2 and PSA, while PSMA decreased ${ }^{3}$. In the current study, we expanded these finding to tumors relapsing several months after $\left[{ }^{225} \mathrm{Ac}\right] \mathrm{hu} 11 \mathrm{~B} 6$ treatment. Compared to treatment naïve tumors, relapsing tumors harbored an altered expression profile of downstream AR-governed biomarkers. Although AR expression remained intact, some of the key AR governed genes (FOLH1, KLK3, PMEPA1 and SPOCK1) were down-regulated while others (KLK2 and TMPRSS2, LONRF1, KCNN2) remained unchanged. Conversely, some of the androgen repressed genes were upregulated (PMP22, CAMK2N1 and UGT2B17). Interestingly, these findings bear a resemblance to the genetic changes reported in glucocorticoid receptor driven enzalutamide resistance ${ }^{10}$. While the underlying radiobiological mechanisms instigating PSMA downregulation during treatment and in recurrent tumors could be different, these observations could potentially explain the reduced treatment efficacy noted upon repeated PSMA targeted RIT and radioligant therapy ${ }^{6,31,32}$. Although preclinical models have limitations, the current outcome demonstrates efficacy of serial $\left[{ }^{225} \mathrm{Ac}\right] \mathrm{hu} 11 \mathrm{~B} 6$ treatment in a mouse model; relapsing tumors in mice express abundant levels of hK2 (KLK2) (Supplemental Figure 2) and were successfully treated by a second activity. Also, more than a year after treatment no imminent organ toxicities were noted at necropsy. 
In addition to deregulated AR regulated genes, further analysis of the transcriptome of relapsing tumors revealed an intriguing profile. Among the most strongly upregulated genes were ETV1, MMP7, TMEFF2, SCHLAP1 and NTS. ETV1 predisposes prostate cells for cooperation with other oncogenic events such as PTEN loss, leading to more aggressive disease in murine models and human patients ${ }^{33}$. ETV1 expression is associated with enrichment of steroid hormone biosynthesis pathway and androgen and estrogen metabolism by binding to HSD17B7, a gene shared by steroid biosynthesis and steroid hormone biosynthesis pathways. In accordance with this, we found $H S D 17 B 7$ to be significantly up-regulated in $\left[{ }^{225} \mathrm{Ac}\right] \mathrm{hu} 11 \mathrm{~B} 6$ resistant tumors $\left(\mathrm{p}=2.27 * 10^{-7}\right) \cdot M M P 7$ is a tumor biomarker associated with increased risk for metastases and poor survival, including prostate cancer ${ }^{34,35}$. TMEFF2 has been reported as an AR-regulated protein ${ }^{36}$ that can function both as an oncogene and as a tumor suppressor by affecting Akt and ERG activation ${ }^{37}$. While the full length intracellular TMEFF2 acts as a tumor suppressor ${ }^{38-40}$, the shed ectodomain promotes growth ${ }^{39}$. Successful immuno-targeting of TMEFF2 expressing PCa tumors has been reported and applied for both positron emission tomography (PET)-imaging and antibody-drug conjugates ${ }^{41-43}$. Therefore, in vivo imaging and co-treatment with TMEFF2targeted compounds could be a potential option to monitor resistance and increase therapeutic efficacy of molecularly targeted alpha-therapy. Similarly, NTS-based radioligands have been developed for theranostic use ${ }^{44,45}$. NTS/ NTS receptor signaling has, amongst others, been associated with prostate cancer exhibiting neuroendocrine features such as down-regulation or loss of AR and PSA ${ }^{46,47}$. Thus, NTS-based imaging and therapy may be an option to monitor transition to to this very aggressive phenotype and to complement $\left[{ }^{225} \mathrm{Ac}\right]$ hu11B6 RIT. Lastly, SCHLAP1 has been shown to be a reliable biomarker strongly associated with a shorter time to metastatic progression, biochemical relapse, and prostate-cancer-specific mortality ${ }^{48-50}$. 
The field of molecularly targeted alpha-therapy is currently undergoing clinical translation, including a planned $\left[{ }^{225} \mathrm{Ac}\right]$ hu11B6 trial. In the current study, we built on previous preclinical studies of hK2-targeted RIT by investigating novel methods to enhance therapeutic efficacy and explore prospective treatment strategies. To the best of our knowledge, this is the first study showing that FcRn-optimized $\mathrm{IgG}_{3}$ subforms can be applied to RIT. Although further studies are needed to replicate our findings, we also discovered a constellation of putative biomarkers associated with resistance to alpha-RIT. 


\section{Methods}

Reagents and cell culture. Reagents were purchased from Sigma-Aldrich unless otherwise noted. Cell growth media were obtained from the Media Preparation Core Facility at Memorial Sloan Kettering Cancer Center (MSKCC, New York, NY). LNCaP-AR (LNCaP cell line with overexpression of wild-type AR and luciferase under the control of the ARR2-Pb promoter) was a kind gift from the laboratory of Dr. Charles Sawyers, which previously developed and reported the cell line ${ }^{51}$. PC3 was purchased from American Type Culture Collection (ATCC). All cell lines were cultured according to the developer's instructions and regularly tested for mycoplasma.

Antibodies. Hu11B6-IgG 1 , hu11B6- $\mathrm{IgG}_{3}{ }^{\mathrm{R} 435 \mathrm{H}}$, hu11B6- $\mathrm{IgG}_{3}$, and hu11B6- $\mathrm{IgG}_{1}{ }^{\mathrm{H} 435 \mathrm{~A}}$ used for an Actinium-225 labeling protocol using two steps were developed by DiaProst AB (Lund, Sweden) and produced by Innovagen AB (Lund, Sweden). Pre DOTA-conjugated hu11B6-IgG 1 applicable for a one step labeling protocol was developed by Diaprost AB (Lund, Sweden) and produced by Fuji-Biosyth (London, England).

Radiochemistry. Carrier-free solid ${ }^{225}$ Actiniumnitrate $\left(5.80 \times 10^{4} \mathrm{Ci} / \mathrm{g} ; 214.6 \times 10^{4} \mathrm{GBq} / \mathrm{g}\right)$, Oak Ridge National Laboratory, Oak Ridge, TN) was assayed at secular equilibrium with a CRC-15R radioisotope calibrator (Capintec, Inc., Florham Park, NJ). All reagents were American Chemical Society reagent grade or better. Radiolabeling procedures were performed using sterile metal-free and pyrogen-free plasticware (Corning, Inc.). The radiometal chelate 1,4,7,10tetraazacyclododecane-1,4,7,10-tetraacetic acid (DOTA) was conjugated to the hu11B6 antibody to yield DOTA-hu11B6 and radiolabeled in one-step as previously described ${ }^{52}$. Briefly, $0.005 \mathrm{~mL}$ of ${ }^{225} \mathrm{Ac}$-nitrate dissolved in $0.2 \mathrm{M} \mathrm{HCl}$ (Fisher Scientific) $(0.1 \mathrm{mCi}$; $3.7 \mathrm{MBq})$ was mixed with 
1.0 to $1.5 \mathrm{mg}$ of DOTA-hu11B6- $\mathrm{IgG}_{1}$ and buffered with $0.1 \mathrm{~mL}$ of $2 \mathrm{M}$ tetramethylammonium acetate and $0.01 \mathrm{~mL}$ of $150 \mathrm{~g} / \mathrm{L}$ of $\mathrm{L}$-ascorbic acid to $\mathrm{pH}$ 5.5. The clear and colorless reaction mixture was heated at $37^{\circ} \mathrm{C}$ for $75-110$ minutes. The reaction was quenched with $0.02 \mathrm{~mL}$ of 50 $\mathrm{mM}$ diethylenetriaminepentaacetic acid and purified via size exclusion chromatography using a Bio-Rad 10DG column stationary phase with a 1\% human serum albumin (HSA, Swiss Red Cross, Bern, Switzerland) and $0.9 \%$ sodium chloride (normal saline solution, Abbott Laboratories, North Chicago, IL) mobile phase. Four combinations of native and mutated, $\mathrm{IgG}_{1}$ and $\mathrm{IgG}_{3}$ isoforms of hu11B6 (i.e., native $\mathrm{IgG}_{1}, \mathrm{H} 435 \mathrm{~A}$ mutant $\mathrm{IgG}_{1}$, wild-type $\mathrm{IgG}_{3}$ and $\mathrm{R} 435 \mathrm{H}$ mutant $\mathrm{IgG}_{3}$ were ${ }^{225}$ Ac-radiolabeled using a previously described two-step method to prepare alpha emitting nanogenerators ${ }^{53}$. Radiochemical purity was determined by instant thin-layer chromatography using silica gel-impregnated paper (Gelman Science Inc., Ann Arbor, MI) using two mobile phases. Mobile phase I was $10 \mathrm{mM}$ ethylenediaminetetraacetic acid; mobile phase II was $9 \%$ sodium chloride/10 mM sodium hydroxide. Activity was measured at secular equilibrium using a Packard gamma counter to count the signal in the 370-510 keV energy window. The binding kinetics of native [ ${ }^{225}$ Ac]DOTA-hu11B6, DOTA-hu11B6, and hu11B6 against recombinant hK2 analyte was measured by surface plasmon resonance (SPR) using a Biacore 2000 (GE Healthcare, Marlborough, MA) as previously described ${ }^{3}$. Antibodies and constructs were captured on a Protein A sensor chip (GE Healthcare) ${ }^{54}$. Antibody capture was performed by diluting each sample to a concentration of $0.001 \mathrm{mg} / \mathrm{mL}$ in HBS-EP buffer (BR100188, GE Healthcare), and flowing the solution over a protein A sensor chip for $1 \mathrm{~min}$. at a flow rate of $0.005 \mathrm{~mL} / \mathrm{min}$. Binding kinetics of antibodies were evaluated across a concentration range of hK2 $(0,3.125,6.25,12.5,25,50$, 100, and $200 \mathrm{nM}$ ) in HBS-EP buffer. The kinetic data was analyzed with Biacore 3.2. 
Animal studies. For xenograft studies, male athymic BALB/c nude mice (NU(NCr)-Foxn1 ${ }^{n u}$; 6-8 weeks old, 20-25 g) were obtained from Charles River. LNCaP-AR tumors were induced in the left and right flanks by s.c. injection of $1-5 \times 10^{6}$ cells in a $200 \mu \mathrm{L}$ cell suspension of a 1:1 vol/vol mixture of medium with Matrigel (Collaborative Biomedical Products, Inc.). Tumors developed after approximately 3-7 weeks. The previously developed Hi-Myc x pb_KLK2_Hi-Myc GEMM, a prostate cancer-susceptible transgenic mouse model prostate tissue specific hK2 expression, was used in the studies ${ }^{12}$. All interventions were performed under anesthesia ( $2 \%$ isoflurane).

Pharmacokinetic tissue distribution. Biodistribution studies were conducted to investigate uptake and pharmacokinetic distribution of various Actinium-225 labeled IgG-subclasses ( $\operatorname{IgG}_{1}$, $\left.\mathrm{IgG}_{1}{ }^{\mathrm{H} 435 \mathrm{~A}}, \mathrm{IgG}_{3}, \mathrm{IgG}_{3}{ }^{\mathrm{R} 435 \mathrm{H}}\right)$ of hu11B6 ([225 Ac]hu11B6) in the GEMM model, and LNCaP-AR and PC3 xenografts. Mice received a single $300 \mathrm{nCi}(11 \mathrm{kBq})$ activity of $\left[{ }^{225} \mathrm{Ac}\right] \mathrm{hu} 11 \mathrm{~B} 6-\mathrm{IgG}_{1}$, $\left[{ }^{225} \mathrm{Ac}\right]$ hu11B6 ${ }^{\mathrm{R} 435 \mathrm{H}}, \quad\left[{ }^{225} \mathrm{Ac}\right] \mathrm{hu} 11 \mathrm{~B} 6-\mathrm{IgG}_{1}$, or $\left[{ }^{225} \mathrm{Ac}\right] \mathrm{hu} 11 \mathrm{~B} 6-\mathrm{IgG}_{1}{ }^{\mathrm{R} 435 \mathrm{H}} \quad(300 \mathrm{nCi}$ on $5 \mu \mathrm{g}$ antibody). Radioimmuno-compounds were administered via intravenous tail-vein injection $(t=0$ hour). Animals ( $\mathrm{n}=4-5$ per group) were euthanized by $\mathrm{CO}_{2}$ asphyxiation at 4, 48, 120 and $360 \mathrm{~h}$ post-injection. Blood was immediately harvested by cardiac puncture. Tissues (including the tumor) were removed, rinsed in water, dried on paper, weighed, and counted on a gamma-counter using a $370-510 \mathrm{keV}$ energy window at secular equilibrium. Aliquots $(0.020 \mathrm{~mL})$ of the injected activities were used as decay correction standards and background signal was subtracted from each sample. The $\% \mathrm{IA} / \mathrm{g}$ was calculated for each animal and data plotted as mean $\pm \mathrm{SD}$.

Therapy studies. In the initial studies, the therapeutic efficacies of $300 \mathrm{nCi}(11 \mathrm{kBq})\left[{ }^{225} \mathrm{Ac}\right]$ on 5 $\mu \mathrm{g}$ hu11B6-IgG 1 , hu11B6- $\operatorname{IgG}_{1}{ }^{\mathrm{H} 435 \mathrm{~A}}$, hu11B6-IgG 3 , and hu11B6 $\operatorname{IgG}_{3}{ }^{\mathrm{R} 435 \mathrm{H}}$, labeled using a two-step 
protocol, were compared in s.c. LNCaP-AR tumors and GEMM. In a subsequent study, two different treatment regimens of labeled hu11B6- $\operatorname{IgG}_{1}$ labeled using a one-step protocol were evaluated; single activity treatment $(600 \mathrm{nCi} ; 22 \mathrm{kBq})$ was compared to fractionated administration $(300+300 \mathrm{nCi} ; 11+11 \mathrm{kBq})\left[{ }^{225} \mathrm{Ac}\right] \mathrm{hu} 11 \mathrm{~B} 6-\mathrm{IgG}_{1}$ in s.c. LNCaP-AR tumors $(5$ mice/treatment group and 5 untreated mice/treatment group). Length (l) and width (w) of the tumors were measured by caliper and tumor volume was calculated using the modified formula for a rotated ellipsoid $\left(V=1 / 2 \mathrm{w}^{2} \mathrm{l}\right){ }^{55}$ was calculated. Weight loss of $20 \%$ or a tumor diameter exceeding $15 \mathrm{~mm}$ was set as an endpoint. Survival percentages over time were calculated to study therapy effectiveness in both studies.

Measurement of kallikreins. Free (fPSA) and total (tPSA) PSA were determined with the duallabel DELFIA immunofluorometric assay (Prostatus ${ }^{\mathrm{TM}}$ PSA Free/Total PSA from Perkin-Elmer Life Sciences Turku, Finland). This assay determines free and complexed PSA in an equimolar fashion, and the cross-reaction for PSA- alpha 1-antichymotrypsin (PSA-ACT) in the fPSA assay is below $0.2 \%{ }^{56}$. The lower limit of detection for tPSA is $0.10 \mathrm{ng} / \mathrm{ml}$ (coefficient of variation of $5.0 \%$ at $2.32 \mathrm{ng} / \mathrm{mL}$ ) and for fPSA $0.04 \mathrm{ng} / \mathrm{mL}$ (coefficient of variation of $5.9 \%$ at $0.25 \mathrm{ng} / \mathrm{mL}$ ). hK2 was measured using an in-house research assay protocol ${ }^{57}$; the detection limit of the assay is $0.005 \mathrm{ng} / \mathrm{mL}$ with assay imprecision values (mean coefficients of variation) ranging from $5.7 \%$ to $11 \%$ for high and low hK2 controls, respectively.

RNA extraction. RNA from snap frozen LNCaP-AR tumors was extracted using the RNeasy Mini Kit (QIAGEN) according to the instructions provided by the manufacturer. 
Transcriptome sequencing (RNA sequencing). After RiboGreen quantification and quality control by Agilent BioAnalyzer, 500 ng of total RNA underwent polyA selection and TruSeq library preparation according to instructions provided by Illumina (RS-122-2102, TruSeq Stranded mRNA LT Kit) with 8 cycles of PCR. Samples were barcoded and run on a HiSeq 4000 in a 50bp/50bp paired end run, using the HiSeq 3000/4000 SBS Kit (Illumina). An average of 44 million paired reads was generated per sample. Ribosomal reads represented maximally $1.2 \%$ of the reads generated and the percent of mRNA bases averaged $63 \%$.

Transcriptome sequencing analysis. Raw read count RNA-sequencing gene expression data for a total of 58,828 genes were acquired from tumor samples treated with $2 \mathrm{x} 300 \mathrm{nCi}(2 \mathrm{x} 11 \mathrm{kBq})$ $\left[{ }^{225} \mathrm{Ac}\right]$ hu11B6- $\operatorname{IgG} 1(\mathrm{n}=3)$ and left untreated $(\mathrm{n}=3)$. After confirming the quality of sequences via FastQC, principal component analysis (PCA) was performed in R, where the PCA plot demonstrated a clear division between the samples from the two cohorts (Supplemental Figure 3). Hierarchical clustering of samples using the Manhattan method for distance calculation further demonstrated a clear divide between the two cohorts. To visualize the magnitude of effect and to highlight the groups of genes that were similar to each other based on their expression, a heatmap was plotted based on the $\log 2$ raw read counts (Supplemental Figure 4).

Differential expression analysis of RNA-sequencing expression profiles was performed using Bioconductor's edgeR ${ }^{58}$ package in R. edgeR implements statistical methods based on negative binomial distributions, namely empirical Bayes methods, that permit the estimation of gene-specific biological variation, even for experiments with minimal levels of biological replication. Raw read counts are provided as input where edgeR introduces possible bias sources into the statistical model to perform an integrated normalization followed by differential 
expression analysis. P-values and fold change in $\log 2$ were calculated for each gene. P-values were adjusted for False Discovery Rate (FDR) using the Benjamini-Hochberg method. Differentially expressed genes were then selected based on the following criteria: Adjusted p-value $<0.001$ and absolute value of $\log 2$ fold change $>2$. A positive fold change represented upregulation, whereas a negative fold change represented down-regulation in tumor samples treated with $\left.{ }^{225} \mathrm{Ac}\right]$ hu11B6-IgG ${ }^{1}$.

Statistics. All statistical analysis of data, except for analysis of RNA-sequencing data (see paragraph above), was performed using Prism software (Graphpad Software Inc, La Jolla, CA). Data are represented as mean $\pm \mathrm{SD}$ or median and range (survival data) ( $\mathrm{n} \geq 3$ independent samples/group for all analyses). No datapoints were excluded from analysis. Unpaired, two-tailed t-tests were used for comparison of two groups. Analysis of survival data was performed by the log-rank test (Mantel-Cox). A p-value<0.05 was considered to indicate statistical significant differences.

Ethical approval. All animal experiments were conducted in compliance with institutional Animal Care and Use Committee (IACUC)-established guidelines at MSKCC and under supervision by the MSKCC Research Animal Resource Center. 


\section{Author Contributions}

Conception and design: David Ulmert, Robert J. Klein

Development of methodology: Sven-Erik Strand, Hans Lilja, Christin Malmborg Hager, Michael R McDevitt, Robert J. Klein, David Ulmert

Acquisition of data (provided animals, acquired and managed patients, provided facilities, etc.): Steven M Larson, Hans Lilja, David Ulmert, Michael R McDevitt, Robert J. Klein

Analysis and interpretation of data (e.g., statistical analysis, biostatistics, computational analysis): Mesude Bicak, Katharina Lückerath, Michael R McDevitt, Robert J. Klein, David Ulmert

Writing, review, and/or revision of the manuscript: Mesude Bicak, Katharina Lückerath, Teja Kalidindi, Sven-Erik Strand, Michael Morris, Caius Radu, Robert Damoiseaux, Norbert Peekhaus, Austin Ho, Darren Veach, Ann-Christin Malmborg Hager, Steven M Larson, Hans Lilja, Michael R McDevitt, Robert J. Klein, David Ulmert

Administrative, technical, or material support (i.e., reporting or organizing data, constructing databases): Mesude Bicak, Katharina Lückerath, Robert J. Klein, David Ulmert

Study supervision: Steven M Larson, Michael R McDevitt, Robert J. Klein, David Ulmert 


\section{References}

1. Kratochwil C, Bruchertseifer F, Rathke H, et al. Targeted Alpha Therapy of mCRPC with (225)Actinium-PSMA-617: Swimmer-Plot analysis suggests efficacy regarding duration of tumor-control. J Nucl Med. 2018.

2. Sathekge M, Bruchertseifer F, Vorster M, et al. Predictors of overall and disease free survival in metastatic castration-resistant prostate cancer patients receiving (225)Ac-PSMA-617 radioligand therapy. J Nucl Med. 2019.

3. McDevitt MR, Thorek DLJ, Hashimoto T, et al. Feed-forward alpha particle radiotherapy ablates androgen receptor-addicted prostate cancer. Nat Commun. 2018;9(1):1629.

4. Kratochwil C, Bruchertseifer F, Rathke H, et al. Targeted alpha-Therapy of Metastatic Castration-Resistant Prostate Cancer with (225)Ac-PSMA-617: Dosimetry Estimate and Empiric Dose Finding. J Nucl Med. 2017;58(10):1624-1631.

5. Rathke H, Kratochwil C, Hohenberger R, et al. Initial clinical experience performing sialendoscopy for salivary gland protection in patients undergoing (225)Ac-PSMA-617 RLT. Eur J Nucl Med Mol Imaging. 2019;46(1):139-147.

6. Evans MJ, Smith-Jones PM, Wongvipat J, et al. Noninvasive measurement of androgen receptor signaling with a positron-emitting radiopharmaceutical that targets prostate-specific membrane antigen. Proc Natl Acad Sci U S A. 2011;108(23):9578-9582.

7. Hope TA, Truillet C, Ehman EC, et al. 68Ga-PSMA-11 PET Imaging of Response to Androgen Receptor Inhibition: First Human Experience. J Nucl Med. 2017;58(1):81-84.

8. Mannweiler S, Amersdorfer P, Trajanoski S, Terrett JA, King D, Mehes G. Heterogeneity of prostate-specific membrane antigen (PSMA) expression in prostate carcinoma with distant metastasis. Pathol Oncol Res. 2009;15(2):167-172.

9. Hupe MC, Philippi C, Roth D, et al. Expression of Prostate-Specific Membrane Antigen (PSMA) on Biopsies Is an Independent Risk Stratifier of Prostate Cancer Patients at Time of Initial Diagnosis. Front Oncol. 2018;8:623.

10. Arora VK, Schenkein E, Murali R, et al. Glucocorticoid receptor confers resistance to antiandrogens by bypassing androgen receptor blockade. Cell. 2013;155(6):1309-1322.

11. Thorek DLJ, Ku AT, Mitsiades N, et al. Harnessing Androgen Receptor Pathway Activation for Targeted Alpha Particle Radioimmunotherapy of Breast Cancer. Clin Cancer Res. 2019;25(2):881-891.

12. Thorek DL, Watson PA, Lee SG, et al. Internalization of secreted antigen-targeted antibodies by the neonatal Fc receptor for precision imaging of the androgen receptor axis. Sci Transl Med. 2016;8(367):367ra167.

13. Vilhelmsson Timmermand O, Larsson E, Ulmert D, Tran TA, Strand S. Radioimmunotherapy of prostate cancer targeting human kallikrein-related peptidase 2. EJNMMI Res. 2016;6(1):27.

14. Timmermand OV, Ulmert D, Evans-Axelsson S, et al. Preclinical imaging of kallikrein-related peptidase 2 (hK2) in prostate cancer with a (111)In-radiolabelled monoclonal antibody, 11B6. EJNMMI Res. 2014;4(1):51.

15. Burmeister WP, Huber AH, Bjorkman PJ. Crystal structure of the complex of rat neonatal Fc receptor with Fc. Nature. 1994;372(6504):379-383. 
16. Salfeld JG. Isotype selection in antibody engineering. Nat Biotechnol. 2007;25(12):1369-1372.

17. Natsume A, In M, Takamura H, et al. Engineered antibodies of IgG1/IgG3 mixed isotype with enhanced cytotoxic activities. Cancer Res. 2008;68(10):3863-3872.

18. Bruhns P, Iannascoli B, England P, et al. Specificity and affinity of human Fcgamma receptors and their polymorphic variants for human IgG subclasses. Blood. 2009;113(16):3716-3725.

19. Scher HI, Fizazi K, Saad F, et al. Increased survival with enzalutamide in prostate cancer after chemotherapy. N Engl J Med. 2012;367(13):1187-1197.

20. de Bono JS, Logothetis CJ, Molina A, et al. Abiraterone and increased survival in metastatic prostate cancer. N Engl J Med. 2011;364(21):1995-2005.

21. Burnette B, Weichselbaum RR. Radiation as an immune modulator. Semin Radiat Oncol. 2013;23(4):273-280.

22. Stapleton NM, Andersen JT, Stemerding AM, et al. Competition for FcRn-mediated transport gives rise to short half-life of human IgG3 and offers therapeutic potential. Nat Commun. 2011;2:599.

23. Jefferis R. Antibody therapeutics: isotype and glycoform selection. Expert Opin Biol Ther. 2007;7(9):1401-1413.

24. Weng WK, Levy R. Two immunoglobulin G fragment C receptor polymorphisms independently predict response to rituximab in patients with follicular lymphoma. J Clin Oncol. 2003;21(21):3940-3947.

25. Nimmerjahn F, Bruhns P, Horiuchi K, Ravetch JV. FcgammaRIV: a novel FcR with distinct IgG subclass specificity. Immunity. 2005;23(1):41-51.

26. Wu AM. Engineered antibodies for molecular imaging of cancer. Methods. 2014;65(1):139147.

27. Bournazos S, Wang TT, Dahan R, Maamary J, Ravetch JV. Signaling by Antibodies: Recent Progress. Annu Rev Immunol. 2017;35:285-311.

28. Simpson TR, Li F, Montalvo-Ortiz W, et al. Fc-dependent depletion of tumor-infiltrating regulatory $\mathrm{T}$ cells co-defines the efficacy of anti-CTLA-4 therapy against melanoma. $J \operatorname{Exp}$ Med. 2013;210(9):1695-1710.

29. Twyman-Saint Victor C, Rech AJ, Maity A, et al. Radiation and dual checkpoint blockade activate non-redundant immune mechanisms in cancer. Nature. 2015;520(7547):373-377.

30. Timmermand OV, Elgqvist J, Beattie KA, et al. Preclinical efficacy of hK2 targeted [(177)Lu]hu11B6 for prostate cancer theranostics. Theranostics. 2019;9(8):2129-2142.

31. Gafita A, Rauscher I, Retz M, et al. Early Experience of Rechallenge (177)Lu-PSMA Radioligand Therapy After an Initial Good Response in Patients with Advanced Prostate Cancer. J Nucl Med. 2019;60(5):644-648.

32. Afshar-Oromieh A, Haberkorn U, Zechmann C, et al. Repeated PSMA-targeting radioligand therapy of metastatic prostate cancer with (131)I-MIP-1095. Eur J Nucl Med Mol Imaging. 2017;44(6):950-959.

33. Baena E, Shao Z, Linn DE, et al. ETV1 directs androgen metabolism and confers aggressive prostate cancer in targeted mice and patients. Genes Dev. 2013;27(6):683-698. 
34. Bialkowska K, Marciniak W, Muszynska M, et al. Association of zinc level and polymorphism in MMP-7 gene with prostate cancer in Polish population. PLoS One. 2018;13(7):e0201065.

35. Ii M, Yamamoto H, Adachi Y, Maruyama Y, Shinomura Y. Role of matrix metalloproteinase7 (matrilysin) in human cancer invasion, apoptosis, growth, and angiogenesis. Exp Biol Med (Maywood). 2006;231(1):20-27.

36. Overcash RF, Chappell VA, Green T, Geyer CB, Asch AS, Ruiz-Echevarria MJ. Androgen signaling promotes translation of TMEFF2 in prostate cancer cells via phosphorylation of the alpha subunit of the translation initiation factor 2. PLoS One. 2013;8(2):e55257.

37. Chen X, Ruiz-Echevarria MJ. TMEFF2 modulates the AKT and ERK signaling pathways. Int J Biochem Mol Biol. 2013;4(2):83-94.

38. Gery S, Sawyers CL, Agus DB, Said JW, Koeffler HP. TMEFF2 is an androgen-regulated gene exhibiting antiproliferative effects in prostate cancer cells. Oncogene. 2002;21(31):4739-4746.

39. Chen X, Overcash R, Green T, Hoffman D, Asch AS, Ruiz-Echevarria MJ. The tumor suppressor activity of the transmembrane protein with epidermal growth factor and two follistatin motifs 2 (TMEFF2) correlates with its ability to modulate sarcosine levels. J Biol Chem. 2011;286(18):16091-16100.

40. Green T, Chen X, Ryan S, Asch AS, Ruiz-Echevarria MJ. TMEFF2 and SARDH cooperate to modulate one-carbon metabolism and invasion of prostate cancer cells. Prostate. 2013;73(14):1561-1575.

41. Williams SP, Ogasawara A, Tinianow JN, et al. ImmunoPET helps predicting the efficacy of antibody-drug conjugates targeting TENB2 and STEAP1. Oncotarget. 2016;7(18):2510325112.

42. Boswell CA, Mundo EE, Zhang C, et al. Differential effects of predosing on tumor and tissue uptake of an 111In-labeled anti-TENB2 antibody-drug conjugate. $J$ Nucl Med. 2012;53(9):1454-1461.

43. Boswell CA, Mundo EE, Firestein R, et al. An integrated approach to identify normal tissue expression of targets for antibody-drug conjugates: case study of TENB2. $\mathrm{Br} J$ Pharmacol. 2013;168(2):445-457.

44. Schulz J, Rohracker M, Stiebler M, et al. Proof of Therapeutic Efficacy of a (177)Lu-Labeled Neurotensin Receptor 1 Antagonist in a Colon Carcinoma Xenograft Model. J Nucl Med. 2017;58(6):936-941.

45. He T, Wang M, Wang $\mathrm{H}$, et al. Evaluation of neurotensin receptor 1 as potential biomarker for prostate cancer theranostic use. Eur J Nucl Med Mol Imaging. 2019;46(10):2199-2207.

46. Bluemn EG, Coleman IM, Lucas JM, et al. Androgen Receptor Pathway-Independent Prostate Cancer Is Sustained through FGF Signaling. Cancer Cell. 2017;32(4):474-489.e476.

47. Abida W, Cyrta J, Heller G, et al. Genomic correlates of clinical outcome in advanced prostate cancer. Proc Natl Acad Sci U S A. 2019;116(23):11428-11436.

48. Prensner JR, Zhao S, Erho N, et al. RNA biomarkers associated with metastatic progression in prostate cancer: a multi-institutional high-throughput analysis of SChLAP1. Lancet Oncol. 2014;15(13):1469-1480.

49. Mehra R, Udager AM, Ahearn TU, et al. Overexpression of the Long Non-coding RNA SChLAP1 Independently Predicts Lethal Prostate Cancer. Eur Urol. 2016;70(4):549-552. 
50. Chua MLK, Lo W, Pintilie M, et al. A Prostate Cancer "Nimbosus": Genomic Instability and SChLAP1 Dysregulation Underpin Aggression of Intraductal and Cribriform Subpathologies. Eur Urol. 2017;72(5):665-674.

51. Chen CD, Welsbie DS, Tran C, et al. Molecular determinants of resistance to antiandrogen therapy. Nat Med. 2004;10(1):33-39.

52. Maguire WF, McDevitt MR, Smith-Jones PM, Scheinberg DA. Efficient 1-step radiolabeling of monoclonal antibodies to high specific activity with $225 \mathrm{Ac}$ for alpha-particle radioimmunotherapy of cancer. $J$ Nucl Med. 2014;55(9):1492-1498.

53. McDevitt MR, Ma D, Lai LT, et al. Tumor therapy with targeted atomic nanogenerators. Science. 2001;294(5546):1537-1540.

54. Holland D, Amadeo RJJ, Wolfe S, et al. Effect of dexamethasone dose and route on the duration of interscalene brachial plexus block for outpatient arthroscopic shoulder surgery: a randomized controlled trial. Can J Anaesth. 2018;65(1):34-45.

55. Tomayko MM, Reynolds CP. Determination of subcutaneous tumor size in athymic (nude) mice. Cancer Chemother Pharmacol. 1989;24(3):148-154.

56. Piironen T, Lovgren J, Karp M, et al. Immunofluorometric assay for sensitive and specific measurement of human prostatic glandular kallikrein (hK2) in serum. Clin Chem. 1996;42(7):1034-1041.

57. Vaisanen V, Eriksson S, Ivaska KK, Lilja H, Nurmi M, Pettersson K. Development of sensitive immunoassays for free and total human glandular kallikrein 2. Clin Chem. 2004;50(9):16071617.

58. Robinson MD, McCarthy DJ, Smyth GK. edgeR: a Bioconductor package for differential expression analysis of digital gene expression data. Bioinformatics. 2010;26(1):139-140. 


\section{Figures}

A

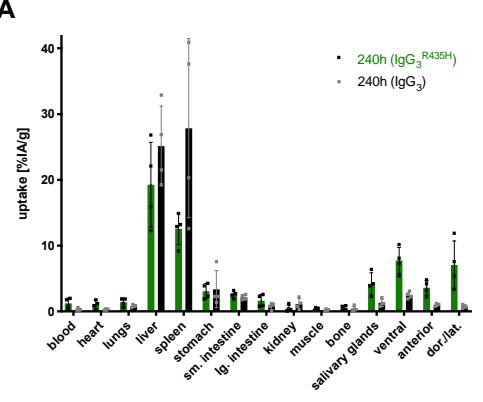

B

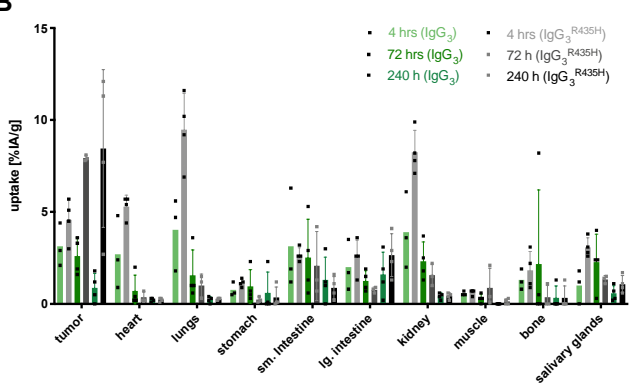

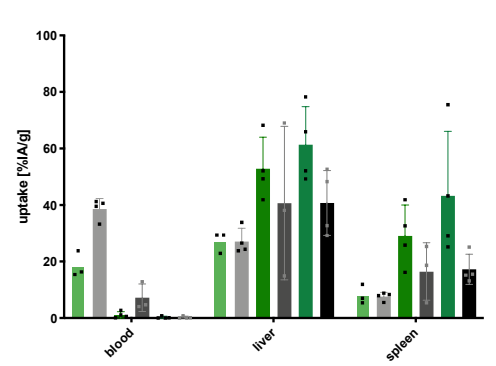

Figure 1. Favorable biodistribution of FcRn optimized $\left[{ }^{225} \mathrm{Ac}\right] \mathrm{hu11B6-IgG3}{ }^{\mathrm{R} 435 \mathrm{H}}$. Mice received $300 \mathrm{nCi}(11 \mathrm{kBq})\left[{ }^{225} \mathrm{Ac}\right] \mathrm{hu} 11 \mathrm{~B} 6-\mathrm{IgG} 3$ or $\left[{ }^{225} \mathrm{Ac}\right] \mathrm{hu} 11 \mathrm{~B} 6-\mathrm{IgG}_{3}{ }^{\mathrm{R} 435 \mathrm{H}}$. Organs were collected at indicated time points (h) and specific uptake (\%IA/g) was determined with a gammacounter. (A) Hi-Myc_KLK2 GEMM. (B) LNCaP-AR xenografts. For better visualization, biodistribution data are shown in two separate graphs with different y-axis scales. Columns and bars represent mean $\pm \mathrm{SD}$ ( $\mathrm{n}=5$ mice/group). Individual values are shown as squares. [225Ac]hu11B6-IgG3 treatment: light green - $4 \mathrm{~h}$; middle green - $48 \mathrm{~h}$; dark green - $240 \mathrm{~h}$. $\left.{ }^{225} \mathrm{Ac}\right]$ hu11B6-IgG ${ }_{3}^{\mathrm{R} 435 \mathrm{H}}$ : light grey - $4 \mathrm{~h}$; middle grey - $48 \mathrm{~h}$; dark grey - 240 h. dor./lat. - dorsal and lateral prostate; lge. int. - large intestine; sm. intestine - small intestine 
A

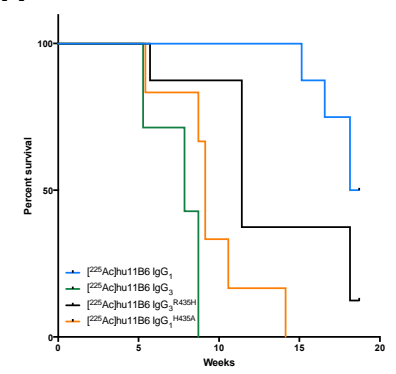

B

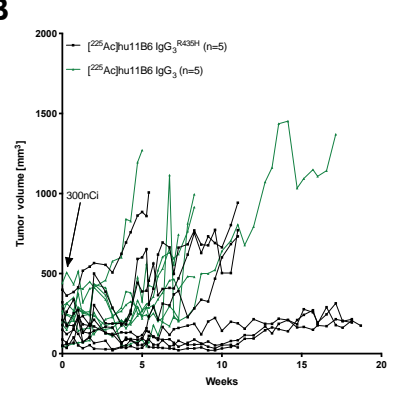

C

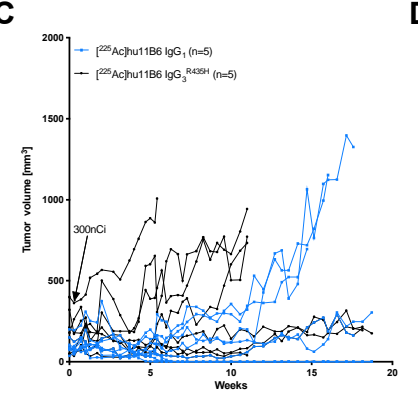

D

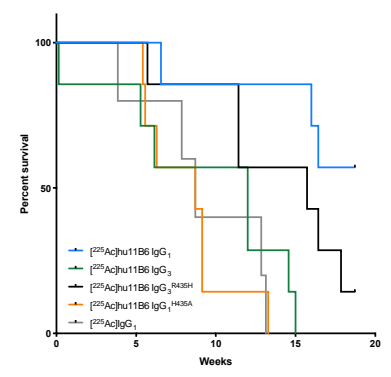

Figure 2. The impact of IgG subclass on $\left[{ }^{225} \mathrm{Ac}\right] \mathrm{hu11B6}$ alpha-radioimmunotherapy. (A-C)

Mice with LNCaP-AR s.c. xenografts were randomized to receive $300 \mathrm{nCi}(11 \mathrm{kBq})$ $\left[{ }^{225} \mathrm{Ac}\right]$ hu11B6- $\operatorname{IgG} 1 \quad(\mathrm{n}=5 ; \quad$ blue $),\left[{ }^{225} \mathrm{Ac}\right] \mathrm{hu} 11 \mathrm{~B} 6-\mathrm{IgG}_{1}{ }^{\mathrm{H} 435 \mathrm{~A}} \quad(\mathrm{n}=5 ; \quad$ orange $), \quad\left[{ }^{225} \mathrm{Ac}\right] \mathrm{hu} 11 \mathrm{~B} 6-$ $\mathrm{IgG}_{3}{ }^{\mathrm{R} 435 \mathrm{H}}$ ( $\mathrm{n}=5$; black) or $\left[{ }^{225} \mathrm{Ac}\right]$ hu11B6-IgG 3 ( $\mathrm{n}=5$; green). (A) Kaplan-Meier curves for survival. (B) Tumor volumes in individual mice following treatment with $\mathrm{IgG}_{3}$ or $\mathrm{IgG}_{3}{ }^{\mathrm{R} 435 \mathrm{H}}$ antibodies, respectively. (C) Tumor volumes in individual mice following treatment with $\mathrm{IgG}_{1}$ or $\mathrm{IgG}_{1} \mathrm{H}^{435 \mathrm{~A}}$ antibodies, respectively. (D) Kaplan-Meier curves for survival of Hi-Myc_KLK2 GEMM following treatment with $300 \mathrm{nCi}(11 \mathrm{kBq})\left[{ }^{225} \mathrm{Ac}\right] \mathrm{hu} 11 \mathrm{~B} 6-\mathrm{IgG}_{1}\left(\mathrm{n}=7\right.$; blue), $\left[{ }^{225} \mathrm{Ac}\right] \mathrm{hu} 11 \mathrm{~B} 6-$ $\mathrm{IgG}_{1}{ }^{\mathrm{H} 435 \mathrm{~A}}$ ( $\mathrm{n}=7$; orange), $\left[{ }^{225} \mathrm{Ac}\right]$ hu11B6- $\mathrm{IgG}_{3}{ }^{\mathrm{R} 435 \mathrm{H}}$ (n=7; black), $\left[{ }^{225} \mathrm{Ac}\right]$ hu11B6-IgG 3 ( $\mathrm{n}=7$; green) or non-specific $\left[{ }^{225} \mathrm{Ac}\right] \operatorname{IgG} \mathrm{I}_{1}(\mathrm{n}=5$; grey). 
A

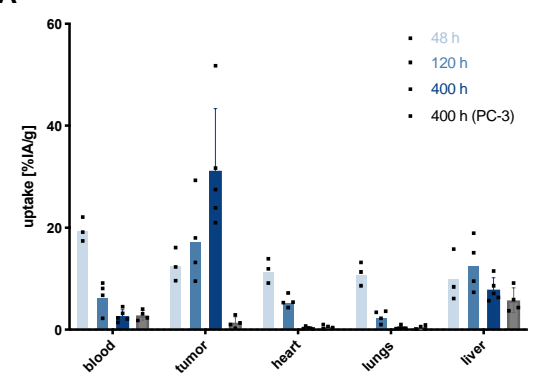

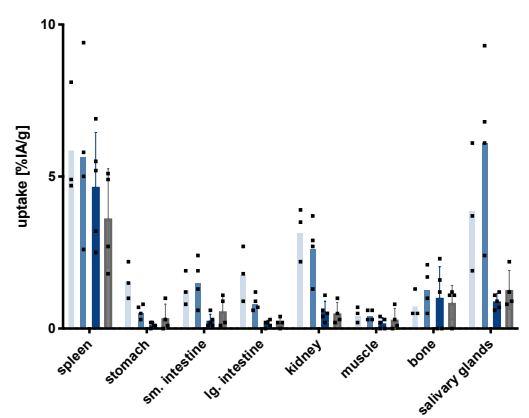

B

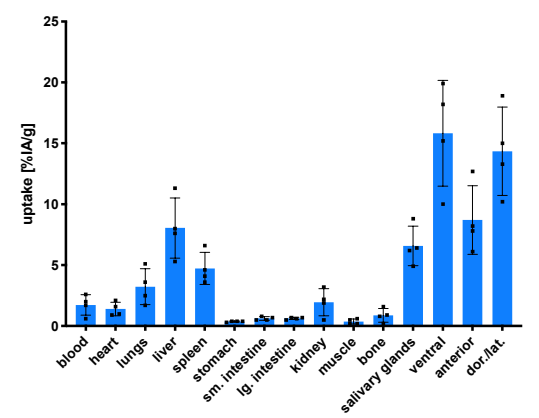

Figure 3. Biodistribution of $\left[{ }^{225} \mathrm{Ac}\right]$ hu11B6-IgG1, labeled using a 1-step protocol. Mice received $300 \mathrm{nCi}(11 \mathrm{kBq})\left[{ }^{225} \mathrm{Ac}\right]$ hu11B6-IgG1. Organs were collected at indicated time points and specific uptake (\%IA/g) was determined in a gamma-counter. (A) LNCaP-AR and PC-3 xenografts. LNCaP-AR are shown in blue: light blue - 48 h; middle blue - 120 h; dark blue - 400 h. PC-3 are shown in grey (400 h). For better visualization, biodistribution data are shown in two separate graphs with different y-axis scales. (B) Hi-Myc_KLK2 GEMM, $400 \mathrm{~h}$ time point. Columns and bars represent the mean $\pm \mathrm{SD}$ ( $\mathrm{n}=5$ mice/group). Individual values are shown as black squares. Time indicates time post radioligand injection. dor./lat. - dorsal and lateral prostate; lge. int. - large intestine; sm. intestine - small intestine 
A

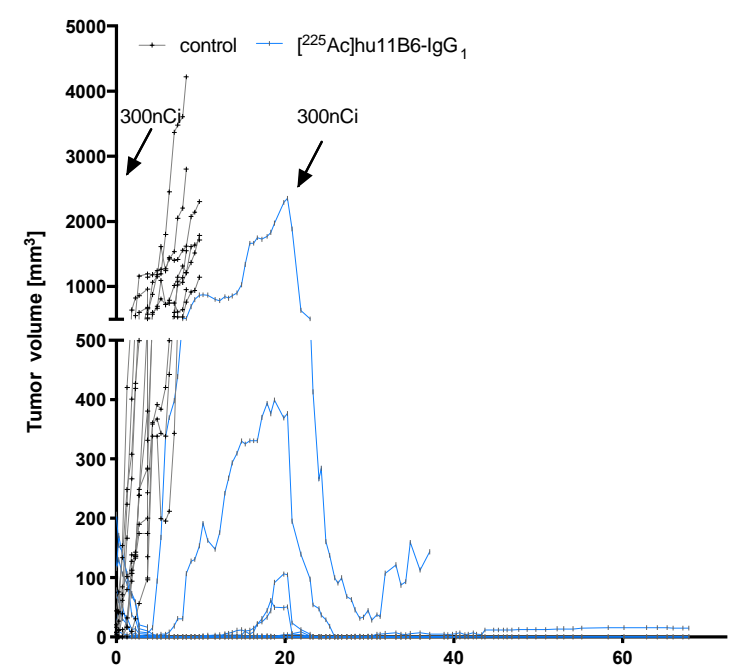

C

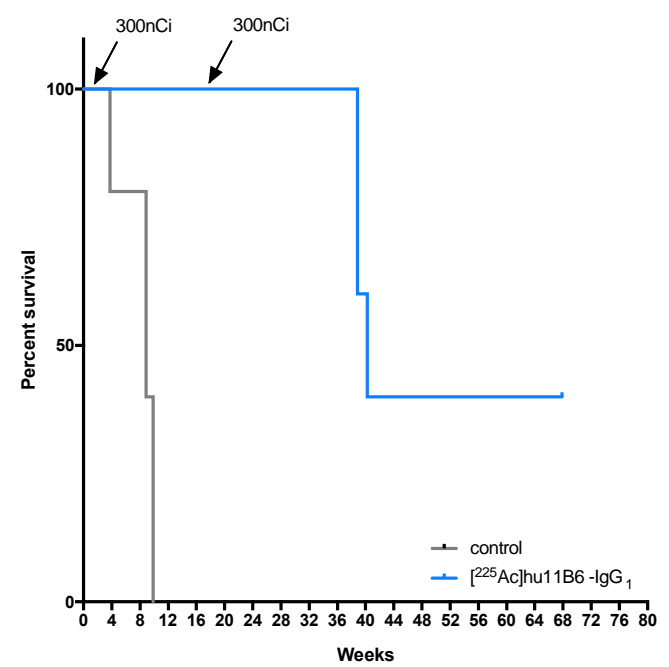

B

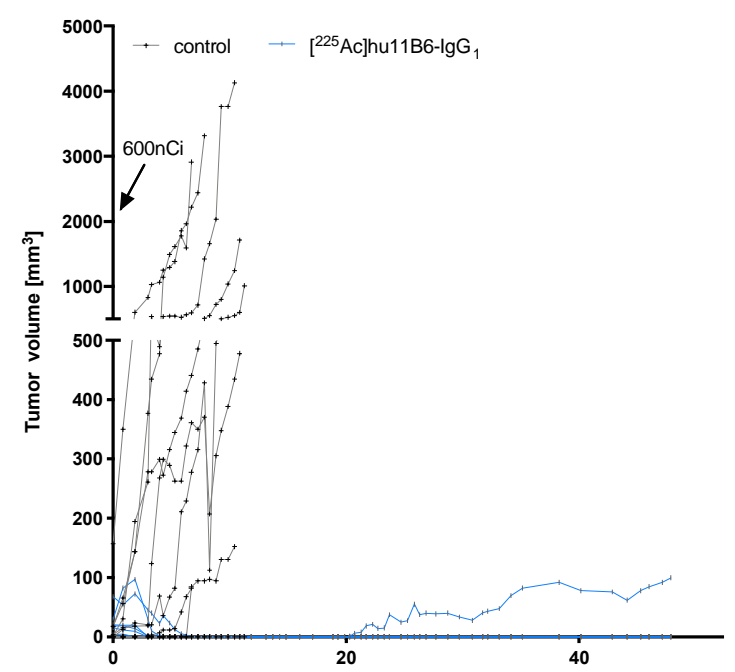

D

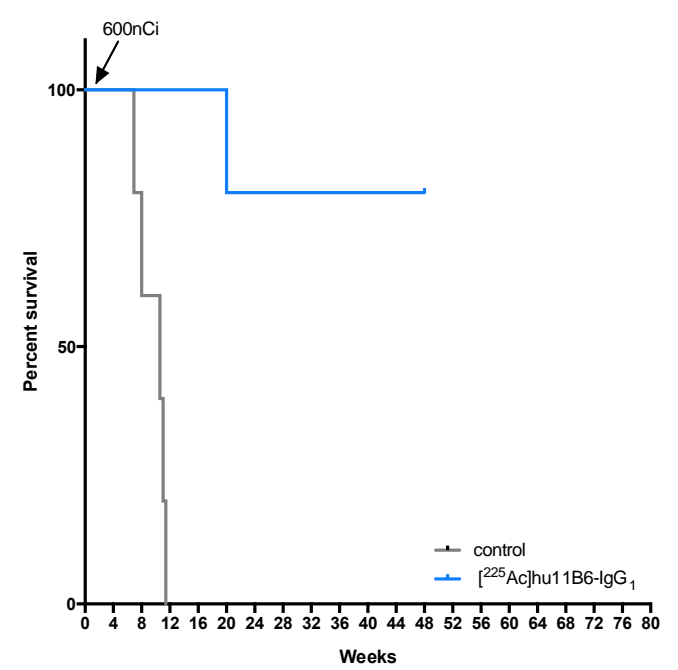

Figure 4. Therapeutic efficacy of fractionated vs. single high-dose $\left[{ }^{225} \mathrm{Ac}\right] \mathrm{hu11B6}-\mathrm{IgG}_{1}$ alpharadioimmunotherapy. Mice with LNCaP-AR s.c. xenografts ( $\mathrm{n}=5$ mice/group) received 2x 300 nCi $\left(2 \mathrm{x} 11 \mathrm{kBq} ; \sim 4.5\right.$ month apart) $(\mathbf{A}, \mathbf{C})$ or $\left.1 \mathrm{x} 600 \mathrm{nCi}(22 \mathrm{kBq})(\mathbf{B}, \mathbf{D}){ }^{225} \mathrm{Ac}\right] \mathrm{hu} 11 \mathrm{~B} 6-\operatorname{IgG} 1$ (blue; vs. untreated, black). (A, B) Tumor volumes of treated and control mice. (C, D) Kaplan Meier analysis of survival of treated and control mice. 


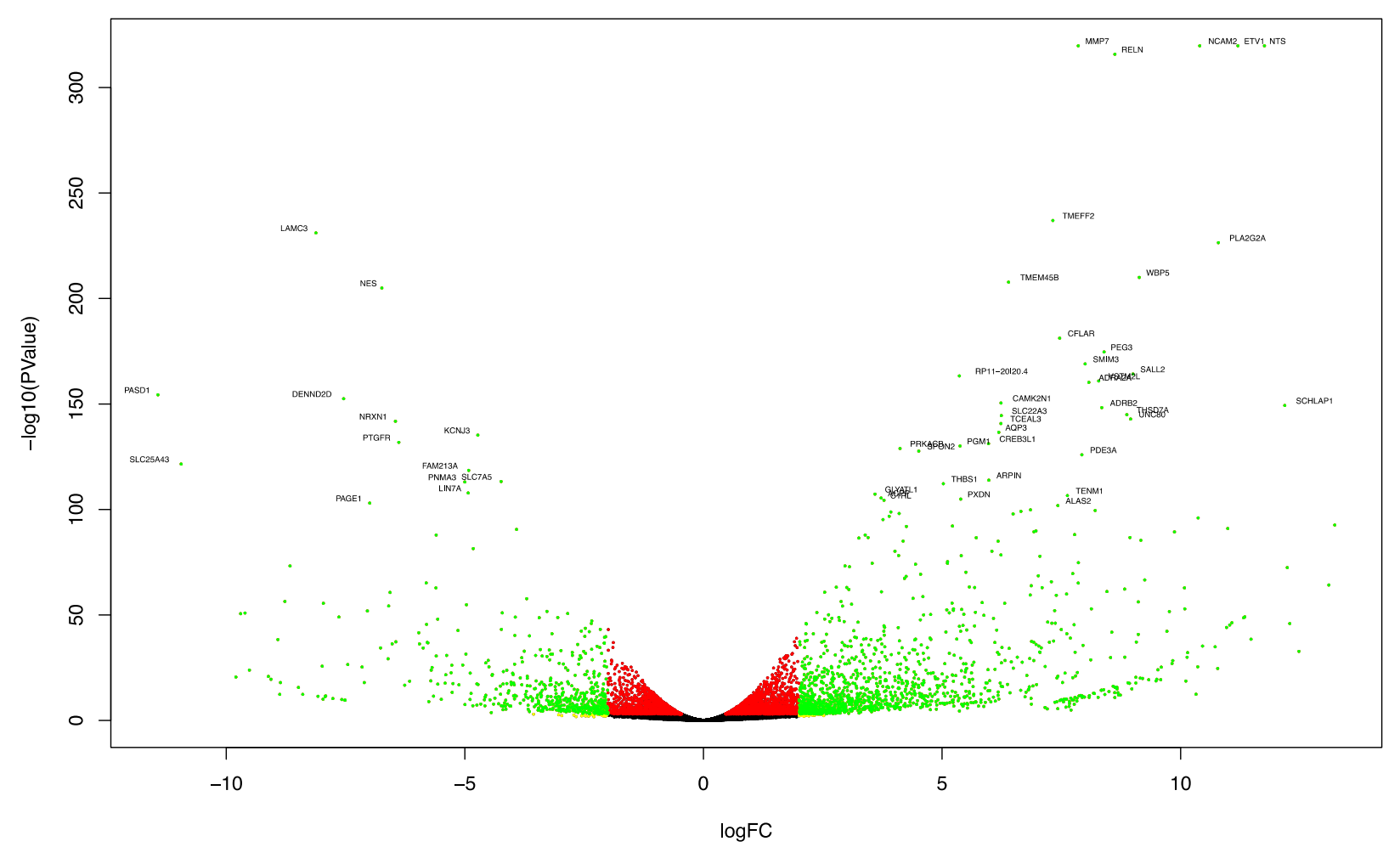

Figure 5. Summary of the RNA-sequencing results by volcano plot representation of differentially expressed genes (DEG). The $x$-axis shows $\log 2$ fold-changes in expression and the $\mathrm{y}$-axis the $\log 10 \mathrm{p}$-values of a gene being differentially expressed. Top 50 DEGs are labeled. Green dots represent DEGs with $\mathrm{p}<0.001$ and absolute value of $\log 2$ fold change $>2$; yellow dots represent those with only absolute value of $\log 2$ fold change $>2$; red dots represent those with only $\mathrm{p}<0.001$. 


\section{Tables}

Table 1. Differentially regulated genes associated with PCa and AR signaling.

\begin{tabular}{|lccc|}
\hline Gene Name & Fold Change $($ Log 2$)$ & P-Value & Adjusted P-Value \\
\hline AR & -0.16 & 0.3125 & 0.89 \\
canonical aggressive PCa genes & & \\
MMP7 & 7.86 & $0.00 \mathrm{E}+00$ & $0.00 \mathrm{E}+00$ \\
\hline ETV1 & 10.58 & $0.00 \mathrm{E}+00$ & $0.00 \mathrm{E}+00$ \\
\hline NTS & 11.76 & $0.00 \mathrm{E}+00$ & $0.00 \mathrm{E}+00$ \\
\hline SCHLAP1 & -12.18 & $3.20 \times 10^{-150}$ & $3.39 \times 10^{-147}$ \\
\hline Androgen-repressed genes & & \\
\hline CAMK2N1 & -6.24 & $4.17 \times 10^{-150}$ & $4.22 \times 10^{-147}$ \\
\hline UGT2B17 & -3.80 & $4.67 \times 10^{-45}$ & $5.43 \times 10^{-43}$ \\
\hline PMP22 & 1.57 & $1.40 \times 10^{-5}$ & $8.96 \times 10^{-5}$ \\
\hline AR-regulated genes & & & 0.0183 \\
\hline TMEFF2 & 7.32 & $1.08 \times 10^{-273}$ & $4.00 \times 10^{-234}$ \\
\hline PMEPA1 & -1.54 & $2.34 \times 10^{-20}$ & $2.35 \times 10^{-18}$ \\
\hline KLK3 & -1.68 & $1.95 \times 10^{-16}$ & $1.46 \times 10^{-14}$ \\
\hline FOLH1 & -0.82 & $4.00 \times 10^{-7}$ & $9.85 \times 10^{-6}$ \\
\hline SPOCK1 & 0.82 & $2.44 \times 10^{-4}$ & $1.17 \times 10^{-3}$ \\
\hline KLK2 & -0.44 & 0.10 & 0.12 \\
\hline TMPRSS2 & 0.21 & & 0.4319 \\
\hline LONRF1 & & & \\
\hline KCNN2 & & & \\
\hline
\end{tabular}


Table 2. Top 10 up-regulated genes at relapse after treatment with $\left[{ }^{225} \mathrm{Ac}\right] \mathrm{hu11B6-IgG1.}$

\begin{tabular}{|lccc|}
\hline Gene Name & Fold Change $(\log 2)$ & P-Value & Adjusted P-Value \\
\hline MMP7 & 7.86 & $0.00 \mathrm{E}+00$ & $0.00 \mathrm{E}+00$ \\
\hline NCAM2 & 10.54 & $0.00 \mathrm{E}+00$ & $0.00 \mathrm{E}+00$ \\
\hline ETV1 & 10.58 & $0.00 \mathrm{E}+00$ & $0.00 \mathrm{E}+00$ \\
\hline NTS & 11.76 & $0.00 \mathrm{E}+00$ & $0.00 \mathrm{E}+00$ \\
\hline TMEFF2 & 7.32 & $1.08 \times 10^{-273}$ & $4.00 \times 10^{-234}$ \\
\hline PLA2G2A & 10.79 & $3.46 \times 10^{-227}$ & $9.62 \times 10^{-224}$ \\
\hline WBP5 & 9.13 & $1.01 \times 10^{-210}$ & $2.49 \times 10^{-207}$ \\
\hline TMEM45B & 6.39 & $1.78 \times 10^{-208}$ & $3.96 \times 10^{-205}$ \\
\hline CFLAR & 7.47 & $6.56 \times 10^{-182}$ & $1.22 \times 10^{-178}$ \\
\hline PEG3 & 8.40 & $2.22 \times 10^{-175}$ & $3.80 \times 10^{-172}$ \\
\hline
\end{tabular}


Table 3. Top 10 down-regulated genes at relapse after treatment with $\left[{ }^{225} \mathrm{Ac}\right] \mathrm{hu} 11 \mathrm{~B} 6-\mathrm{IgG} 1$.

\begin{tabular}{|lccc|}
\hline Gene Name & Fold Change $(\log 2)$ & P-Value & Adjusted P-Value \\
\hline LAMC3 & -8.12 & $8.02 \times 10^{-232}$ & $2.55 \times 10^{-228}$ \\
\hline NES & -6.743 & $1.08 \times 10^{-205}$ & $2.19 \times 10^{-202}$ \\
\hline PASD1 & -11.43 & $4.53 \times 10^{-155}$ & $5.30 \times 10^{-152}$ \\
\hline DENND2D & -7.54 & $3.34 \times 10^{-153}$ & $3.71 \times 10^{-150}$ \\
\hline NRXN1 & -6.45 & $1.60 \times 10^{-142}$ & $1.31 \times 10^{-139}$ \\
\hline KCNJ3 & -4.73 & $5.93 \times 10^{-136}$ & $4.39 \times 10^{-133}$ \\
\hline PTGFR & -6.38 & $1.50 \times 10^{-132}$ & $1.07 \times 10^{-129}$ \\
\hline SLC25A43 & -10.94 & $2.87 \times 10^{-122}$ & $1.72 \times 10^{-119}$ \\
\hline FAM213A & -4.92 & $2.97 \times 10^{-119}$ & $1.74 \times 10^{-116}$ \\
\hline SLC7A5 & -4.24 & $5.65 \times 10^{-114}$ & $3.14 \times 10^{-111}$ \\
\hline
\end{tabular}

